\title{
Interleukin-17A Promotes Arginase-1 Production and 2,4-Dinitrochlorobenzene-Induced Acute Hyperinflammation in Human Papillomavirus E7 Oncoprotein-Expressing Skin
}

\author{
Le Son Tran ${ }^{a}$ Deepak Mittal ${ }^{b}$ Stephen R. Mattarollo ${ }^{a}$ Ian H. Frazer ${ }^{a}$ \\ a The University of Queensland Diamantina Institute, Translational Research Institute, Brisbane, Qld., and \\ ${ }^{b}$ QIMR Berghofer Medical Research Institute, Herston, QId., Australia
}

\author{
Key Words \\ Bone marrow-derived macrophages . \\ 2,4-Dinitrochlorobenzene $\cdot$ Human papillomavirus $\cdot$ IL-17A . \\ mRNA $\cdot \mathrm{N}^{\omega}$-hydroxy-nor-L-arginine
}

\begin{abstract}
Human papillomaviruses (HPVs) have evoked numerous mechanisms to subvert host innate immunity and establish a local immunosuppressive environment to facilitate persistent virus infection. Topical application of 2,4-dinitrochlorobenzene (DNCB) was speculated to overcome this immunosuppressive environment and was employed in the immunotherapy of HPV-associated lesions. We have previously shown that DNCB treatment of skin expressing HPV16.E7 protein, the major oncogenic protein expressed in HPV-associated premalignant cervical epithelium, results in a hyperinflammatory response, with an associated induction of Th2 cytokines and infiltration of myeloid cells producing arginase-1, which also contributes to the hyperinflammation. However, the molecular mechanisms underlying arginase-1 induction and arginase-mediated hyperinflammation in K14.E7 skin have not been elucidated. Here, we show that HPV16.E7 protein expression as a transgene in skin is associated with enhanced IL-17A production by macrophages exposed to DNCB. Interestingly, induction of arginase-1 by DNCB is not seen in K14.E7 animals unable to express IL-17A.
\end{abstract}

Further, blockade of either IL-17A or arginase activity alleviates DNCB-induced hyperinflammation through reduced recruitment of neutrophils, as a consequence of decreased CXCL1 and CXCL5 chemokine production. Thus, our findings suggest that increased IL-17A expression by macrophages in E7-expressing skin exposed to DNCB promotes arginase-1 induction and contributes directly to the observed hyperinflammation.

(c) 2015 S. Karger AG, Basel

\section{Introduction}

Persistent infection of basal keratinocytes with oncogenic human papillomavirus (HPV), particularly HPV16, causes epidermal dysplasia and eventually squamous cell cancers [1]. Establishment of HPV persistence is associated with its ability to subvert effective innate immunity through the action of two major oncoproteins: E6 and E7 [2].

K14.E7 transgenic mice in which a single viral HPV type 16 E7 oncoprotein is expressed within basal keratinocytes under the control of the keratin 14 transcriptional promoter have been shown to closely mimic the expression pattern of E7 oncoprotein observed in pre-cancerous squamous epithelial lesions caused by HPV $[3,4]$. Therefore, this model has been extensively employed as a model of HPV-associated pre-malignancy to study the mech-

\section{KARGER 125}

(c) 2015 S. Karger AG, Basel

$1662-811 X / 15 / 0074-0392 \$ 39.50 / 0$

E-Mail karger@karger.com

www.karger.com/jin
Prof. Ian H. Frazer

The University of Queensland Diamantina Institute

Translational Research Institute

37 Kent Street, Woolloongabba, Brisbane, QLD 4102 (Australia)

E-Mail i.frazer@uq.edu.au 
anisms of immunosuppression mediated by this early viral oncoprotein [5]. Indeed, previous investigations using this model have revealed that HPV16.E7 oncoprotein induces a localised immunosuppressive environment and that successful therapies need to circumvent or disrupt this environment $[6,7]$.

Stimulation of innate immunity by topical application of 2,4-dinitrochlorobenzene (DNCB), a contact hypersensitiser, was recognised as a promising therapy for resistant warts caused by HPV [8]. The effectiveness of this approach is ascribed to the activation of innate immune defence mechanisms through a strong cutaneous inflammation induced by DNCB [9]. Although clinical application of DNCB has been discouraged due to its potent mutagenic, genotoxic and carcinogenic hazards [10], we hypothesised that understanding how DNCB-induced acute inflammation can alter the local immunosuppressive environment generated by HPV16.E7 oncoprotein might lead to better treatment options for patients with persistent HPV infection. Our recent study showed that treatment of K14.E7 skin with DNCB causes a hyperinflammatory response, which is associated with enhanced recruitment of myeloid cells producing arginase-1, and that arginase- 1 is required for the development of DNCB-induced hyperinflammation [11]. However, the molecular mechanisms regulating arginase- 1 induction, as well as how arginase-1 regulates the hyperinflammation in K14. E7 skin, have not been elucidated.

Th2 cytokines, including IL-4, IL-13 and IL-10, drive the induction of arginase- 1 in myeloid cells through STAT6 transcriptional factor $[12,13]$. In a murine asthma model, Th2 cytokines induced arginase- 1 and allergic airway inflammation [14]. In addition to Th2 cytokines, IL-17A, an important cytokine of innate immunity, has also been shown to induce arginase-1 production in inflammatory macrophages in a model of Leishmania amazonensis infection [15] in vascular inflammation [16] and in a tumour environment [17].

Although IL-17A is primarily produced by T helper 17 cells and other lymphocyte subsets $(\gamma \delta \mathrm{T}$ cells, invariant natural killer $\mathrm{T}$ cells), recent studies have reported that innate immune cells, including neutrophils [18] and macrophages [19], are important cellular sources of IL-17A. IL-17A, which signals through a receptor complex composed of IL-17RA/IL-17RC, mediates skin lesions through induction of chemokines and recruitment of innate immune cells [20].

Since arginase regulation is dependent on a cytokine milieu, the present study aimed to investigate the involvement of these cytokines in the induction of arginase- 1 and the enhanced inflammation in K14.E7 skin. Here, we show that suppression of IL-17A and not Th2 cytokines caused a significant reduction in the production of arginase-1 in K14.E7 skin exposed to DNCB, indicating involvement of IL-17A in arginase-1-mediated hyperinflammation in K14.E7 skin.

In addition, we show that IL-17A is induced by $\mathrm{CD} 11 \mathrm{~b}^{+} \mathrm{F} 4 / 80^{+}$macrophages in the absence of lymphocytes and that IL-17A together with its downstream mediator, arginase-1, participates in ongoing DNCB-induced hyperinflammation in K14.E7 skin through enhanced recruitment of neutrophils. Taken together, our findings demonstrate that IL-17A promotes DNCB-induced hyperinflammatory responses in HPV16.E7 skin concomitant with the induction of arginase activity.

\section{Materials and Methods}

\section{Mice}

HPV16.E7 transgenic C57BL/6 mice (designated K14.E7), which express HPV type 16 E7 oncoprotein under control of keratin 14 promoter, were generated from inbred C57BL/6 mice [21]. Rag1 $1^{-/-}$ and IL-17A $\mathrm{A}^{-/-}$mice were obtained from the Animal Resources Centre (Perth, W.A., Australia) and Prof. Helen Thomas (The University of Melbourne), respectively. E7.Rag ${ }^{-/-}$and E7.IL17 ${ }^{-/-}$were generated by crossing male K14.E7 mice with female $\mathrm{Rag}^{-{ }^{--}}$or IL17A $^{-/-}$knockout C57BL/6 mice, heterozygous K14.E7 mice were crossed and then backcrossed with homozygous Rag $1^{-/-}$or $\mathrm{IL}_{17^{-/-}}$ mice to an F2 generation [21]. K14.hGH mice were purchased from the Animal Resources Centre. All mice on C57BL/6 background were maintained under specific pathogen-free conditions at the Translational Research Institute-Biological Research Facility. Experimental mice were matched for sex and used at 6-9 weeks of age. All animal procedures complied with guidelines approved by the University of Queensland Animal Ethics Committee (AEC 367/13).

\section{Media and Reagents}

Complete medium was DMEM supplemented with $10 \%$ heatinactivated FCS, $1 \%$ penicillin/streptomycin, 1\% L-glutamine, $1 \%$ sodium pyruvate and $1 \%$ HEPES (Gibco, Victoria, S.A., Australia).

Neutralising monoclonal antibodies (mAbs) against IL-4 (rat IgG1, clone 11B11) and IL-10 (rat IgG1, clone JES5-2A5) and isotype-matched control mAb (rat IgG1, clone eBRG1) were purchased from eBioscience (San Diego, Calif., USA). mAb (rat IgG1) against murine IL-17A (LA426) and control isotype-matched rat mAb (2405001) were obtained from Lilly Research Laboratories (Indianapolis, Ind., USA).

Mouse IL-17A (homodimer) enzyme-linked immunosorbent assay (ELISA) Ready-SET-Go kits with a sensitivity limit of 4 pg/ $\mathrm{ml}$ were purchased from eBioscience.

\section{DNCB Treatment}

DNCB (Sigma, Castle Hill, N.S.W., Australia) was dissolved in acetone:olive oil (4:1) immediately prior to use. For IL-17A neutralisation in vivo, 6- to 9-week-old mice were intraperitoneally 
Table 1. PCR primer sequences

\begin{tabular}{lll}
\hline Gene & Forward $5^{\prime}-3^{\prime}$ & Reverse $3^{\prime}-5^{\prime}$ \\
\hline RPL32 & GGTGAAGCCCAAGATCGTC & TTGGGATTGGTGACTCTGATG \\
Arginase-1 & AAGAATGGAAGAGTCAGTGTGG & GGGAGTGTTGATGTCAGTGTG \\
Arginase-2 & GATCTCTGTGTCATCTGGGTTG & AATCCTGGCAGTTGTGGTAC \\
IL-4 & CGAATGTACCAGGAGCCATATC & TCTCTGTGGTGTTCTTCGTTG \\
IL-10 & GGAGTCGGTTAGCAGTATGTTG & AGCCGGGAAGACAATAACTG \\
IL-17A & TCCAGAATGTGAAGGTCAACC & TATCAGGGTCTTCATTGCGG \\
CXCL1 & AACCGAAGTCATAGCCACAC & CAGACGGTGCCATCAGAG \\
CXCL2 & GAAGTCATAGCCACTCTCAAGG & CTTCCGTTGAGGGACAGC \\
CXCL5 & GTTCCATCTCGCCATTCATG & TTAAGCAAACACAACGCAGC \\
\hline
\end{tabular}

administered a dose of $10 \mathrm{mg} / \mathrm{kg}$ of anti-IL-17A blocking antibody or isotype-matched control antibody. After $24 \mathrm{~h}$, the treatment was repeated for $30 \mathrm{~min}$ before applying $20 \mu \mathrm{l}$ of 1 or $10 \%(\mathrm{~m} / \mathrm{v}) \mathrm{DNCB}$ on the left ear and $20 \mu \mathrm{l}$ of vehicle (acetone:olive oil 4:1) on the right ear. The ear tissues were harvested for mRNA, protein and histological analysis $24 \mathrm{~h}$ following DNCB treatment. Ear thickness was measured within 5 consecutive days by using a digital calliper, and change in ear swelling was determined by calculating the mean increase in ear thickness compared to untreated ears.

For arginase suppression, mice were injected with $500 \mu \mathrm{g}$ of arginase inhibitor, nor-NOHA (Cayman, Ann Arbor, Mich., USA) or saline buffer 1 day prior to DNCB treatment and daily for 5 days.

\section{Skin Explant Culture}

Four hours after DNCB exposure, ear skin was excised and split into dorsal and ventral halves, and each ear half was placed dermis side down on $2 \mathrm{ml}$ of complete DMEM, 24-well tissue culture plates at $37^{\circ} \mathrm{C}, 5 \% \mathrm{CO}_{2}$. To reduce the effect of cell death-related release of cytokines and danger signals, after $1 \mathrm{~h}$, the culture medium was exchanged with $2 \mathrm{ml}$ of fresh complete DMEM. For in vitro cytokine neutralisation, culture medium was supplemented with $10 \mathrm{ng} / \mathrm{ml}$ of anti-IL-4, anti-IL-10 or anti-IL-17A neutralising $\mathrm{mAbs}$ and rat IgG1 isotype-matched control mAb. Ear skin explant supernatant was collected after $20 \mathrm{~h}$ and used for bone marrow-derived macrophage (BMDM) stimulation or cytokine production analysis by ELISA.

\section{Preparation and Cultivation of BMDM}

Bone marrow cells were flushed from femurs and tibias of C57BL/6 mice and cultivated in complete DMEM supplemented with $20 \%$ L-cell conditioned medium (kindly provided by Dr. Antje Blumenthal) and cultured at $37^{\circ} \mathrm{C}, 5 \% \mathrm{CO}_{2} ; 5 \mathrm{ml}$ of fresh medium were added to the culture every 2 days. After 6 days, BMDMs were harvested and seeded in complete DMEM at a concentration of $5 \times$ $10^{5}$ cells $/ \mathrm{ml}$, then allowed to recover for $2 \mathrm{~h}$ before performing in vitro stimulation. $\mathrm{mAbs}$ against IL-4, IL-10 or IL-17A and isotypematched control antibodies were added to culture medium $30 \mathrm{~min}$ before stimulating BMDMs with $20 \%$ skin explant supernatant. After $24 \mathrm{~h}$, BMDMs were harvested by using cold $0.05 \%$ EDTA in PBS. Total protein was isolated from sorted cells by resuspending cells in $50 \mu$ of lysis buffer containing $20 \mathrm{~mm}$ Tris, $100 \mathrm{~mm} \mathrm{NaCl}$, $1 \mathrm{mM}$ EDTA, 0.5\% Triton X-100, EDTA-Minicomplete protease inhibitor (Roche Diagnostics, Castle Hill, N.S.W., Australia) and incubation for $30 \mathrm{~min}$. After centrifugation at $13,000 \mathrm{~g}$ at $4^{\circ} \mathrm{C}$ for $20 \mathrm{~min}$, the supernatant was collected for protein quantification determined using the Pierce ${ }^{\mathrm{TM}}$ bicinchoninic acid protein assay (Thermo Fisher Scientific, Rockford, Ill., USA) and then $100 \mu \mathrm{g}$ of protein lysate were used to determine arginase activity.

\section{Arginase Enzymatic Assay}

Arginase activity was measured by colorimetric determination of urea formed from L-arginine as previously described [22].

\section{IL-17A ELISA}

IL-17A production in skin explant supernatant was determined following the manufacturer's instructions. IL-17A concentration in supernatant was normalised to the weight of the skin explant (shown as $\mathrm{pg} / \mathrm{mg}$ tissue).

\section{Real-Time PCR}

Total RNA was isolated from homogenised tissues using the RNaeasy mini kit (Qiagen, Clifton Hill, Vic., Australia). RNA extracts were quantified using absorption of light at 260 and $280 \mathrm{~nm}$. For cDNA synthesis, $500 \mathrm{ng}$ of total RNA were reverse transcribed in $20 \mu$ of reaction mixture containing $5 \mathrm{mM} \mathrm{MgCl}_{2} ; 1.6 \mathrm{mM}$ dNTP mix, $2.5 \mathrm{mM}$ oligo-dT, $1 \mu \mathrm{l}$ of MuLv reverse transcriptase $(5,000$ units, U; Applied Biosystems, Mulgrave, Vic., Australia) and $10 \mathrm{U}$ RNaseOUT (Invitrogen, Mount Waverley, Vic., Australia) at $42^{\circ} \mathrm{C}$ for $60 \mathrm{~min}$. The reactions were heated at $70^{\circ} \mathrm{C}$ for $15 \mathrm{~min}$ to inactivate reverse transcriptase enzyme. cDNA was diluted (1:4), and $2.5 \mu \mathrm{l}$ were subjected to real-time PCR using the SYBR TAKA kit (Thermo Fisher Scientific, Scoresby, Vic., Australia) and primers (Integrated DNA Technologies, Coralville, Iowa, USA) listed in table 1 . The relative expression was determined by normalising against the house keeping gene RPL32 (L32 ribosomal protein gene).

\section{Flow-Cytometric Analysis}

Single-cell suspensions were prepared by incubating minced ear skin tissue in $2 \mathrm{mg} / \mathrm{ml}$ dispase (Roche Diagnostics) for $1 \mathrm{~h}$ and $0.3 \mathrm{mg} / \mathrm{ml}$ collagenase D (Roche Diagnostics) for $30 \mathrm{~min}$ and grinding through a $70-\mu \mathrm{m}$ cell strainer. After adding $\mathrm{Fc} \gamma$ receptor blocking antibody (Fc $\gamma$ III/II receptor, 1/50; BD Biosciences, Auckland, New Zealand) and incubating on ice for $10 \mathrm{~min}$, cells were stained with live/dead aqua dyes (live/dead fixable aqua dead cell stain kit, 1/1,000; Invitrogen) and antibodies specific for the 
following surface markers for $30 \mathrm{~min}$ at $4^{\circ} \mathrm{C}$ : CD45.2-PerCP5.5 (clone 30-F11; eBioscience); CD11b-Pacific Blue (clone M1/70; eBioscience), F4/80-FITC (clone BM8; eBioscience), Gr1(Ly6G/ Ly6C)-APC (clone RB6-8C5; eBioscience), MHCII-APC.Cy7 (clone M5/114.15.2; Biolegend), CD11c-PE.Cy7 (clone HL3; BD Pharmingen) and CD3-PE (clone 17A2; eBioscience). Cells were fixed and permeabilised using the BD Cytofix/Cytoperm kit (BD Pharmingen) according to the manufacturer's instructions before intracellular staining with $\mathrm{mAb}$ against IL-17 A or isotype-matched control antibody (1/100; eBiosciences) for $45 \mathrm{~min}$. For absolute cell counting, Flow-Count fluorospheres (Beckman Coulter, Lane Cove, N.S.W., Australia) were added to stained cells before cell acquisition was performed on an LSR Fortessa II cytometer (BD Biosciences). Data were analysed using Kaluza software (version 1.2; Beckman Coulter).

\section{Histological Analysis}

Ear tissues were fixed in $4 \%$ paraformaldehyde for $24 \mathrm{~h}$. Tissues were embedded in paraffin, and $7-\mu \mathrm{m}$ sections were prepared and stained with haematoxylin and eosin. Immune cell infiltration was evaluated by light microscopy using NIS-Elements Basic Research 3.2 software (Nikon Instruments Inc., New York, N.Y., USA).

Paraffin sections were dewaxed and rehydrated through xylol and descending graded alcohol series to Tris-buffered saline (TBS; $\mathrm{pH}$ 7.6). Endogenous peroxidase activity was blocked by incubating the sections in $2.0 \%$ hydrogen peroxide in TBS for $10 \mathrm{~min}$. After rinsing slides in distilled water, sections were transferred to Biocare Medical Diva retrieval buffer (Biocare Medical, Concord, Calif., USA) and subjected for $15 \mathrm{~min}$ to heat antigen retrieval at $105^{\circ} \mathrm{C}$ using the Biocare Medical Decloaking Chamber. Samples were allowed to cool for $20 \mathrm{~min}$ and washed three times in TBS before anti-mouse F4/80 (1/350; abcam, Cambridge, UK) was added for $90 \mathrm{~min}$ at room temperature. Sections were washed in TBS before adding secondary antibody and the Rat-on-Mouse HRP-Polymer kit (Biocare Medical, Concord, Calif., USA). Colour is developed in $\mathrm{DAB}$ for $5 \mathrm{~min}$ and sections were lightly counterstained in Mayer's haematoxylin, then dehydrated through ascending graded alcohol series, cleared in xylene and mounted using DePeX.

\section{Statistical Analysis}

Data represent means \pm SEM and are representative of two independent experiments with at least 4 mice/group. Prism (Graph Pad Software, La Jolla, Calif., USA) was used for graphs and statistical analysis: ${ }^{*} \mathrm{p}<0.05 ;{ }^{* *} \mathrm{p}<0.01$; $^{* * *} \mathrm{p}<0.001$; ${ }^{* * * *} \mathrm{p}<0.0001$. Multiple comparisons of ear swelling data were performed by twoway ANOVA. For other data, statistically significant differences between groups were analysed by non-parametric test (WilcoxonMann-Whitney test).

\section{Results}

DNCB-Induced IL-17A, but Not IL-4 or IL-10, in

K14.E7 Skin Promotes Macrophage-Induced Arginase Production

We have previously shown that DNCB treatment of skin expressing the E7 protein of HPV.16 as a transgene induces hyperinflammation when compared with similar treatment of non-transgenic skin, and that this is associated with the induction of Th2 cytokines, including IL-4 and IL-10. Th2 cytokines have been described as potent inducers of arginase-1 in monocytes/macrophages, so we assessed the link between each of these cytokines and arginase-1 production in DNCB-treated K14.E7 skin using an in vitro skin explant model. BMDMs were cultured in supernatants harvested from explant cultures of vehicleor DNCB-treated skin from C57BL/6, $\mathrm{Rag}^{-/-}$, K14.E7 or $\mathrm{E} 7 . \mathrm{Rag}^{-/-}$mice. BMDMs exposed to supernatant from DNCB-treated K14.E7 or E7. Rag ${ }^{-/}$skin explants expressed more arginase activity than those exposed to supernatant from vehicle-treated skin explants. By contrast, there was no change in arginase activity when BMDMs were stimulated with supernatants from DNCB-treated wild-type C57BL/6 and $\mathrm{Rag}^{-/-}$skin explants (fig. 1a). These observations confirmed in vitro our previous ex vivo observation that DNCB treatment of K14.E7 skin leads to enhanced arginase activity in inflammatory macrophages by a mechanism independent of $\mathrm{T}$ and $\mathrm{B}$ lymphocytes.

We next tested whether IL-4 or IL-10 released by DNCB-treated K14.E7 ear skin is involved in the induction of arginase-1 in BMDMs by exposing the BMDM cultures to anti-IL- 4 and anti-IL-10 neutralising antibodies. Neutralisation of IL- 4 and IL-10 did not change the level of arginase activity in BMDMs stimulated with supernatant from DNCB-treated K14.E7 skin explants (fig. 1b), demonstrating that IL-4 and IL-10 were not necessary for the enhanced arginase activity in DNCB-treated K14.E7 skin.

Since IL-17A has been shown to induce arginase-1 expression by macrophages in recent studies $[16,17]$, we next investigated whether IL-17A played a role in the induction of arginase in our model. Depletion of IL-17A with neutralising antibody, in contrast to depletion of IL-10 and IL-4, significantly reduced the observed level of arginase activity (fig. 1b). In support of this observation, BMDMs cultured in supernatant from skin explants from DNCB-treated E7.IL17 ${ }^{-/-}$animals produced less arginase activity than those cultured in supernatants from E7.IL17 ${ }^{+/-}$or from K14.E7 skin explants (fig. 1c).

To further confirm a key role for IL-17A in the enhancement of arginase production in response to $\mathrm{DNCB}$, we assessed the in vivo production of arginase in K14.E7 skin and E7.IL17 ${ }^{-/-}$skin after DNCB application. Consistent with our in vitro data, E7.IL17 ${ }^{-/-}$mouse skin treated with DNCB demonstrated significantly less arginase activity and arginase- 1 transcription than K14.E7 mouse skin (fig. 2a, b). Arginase-2 mRNA tran- 


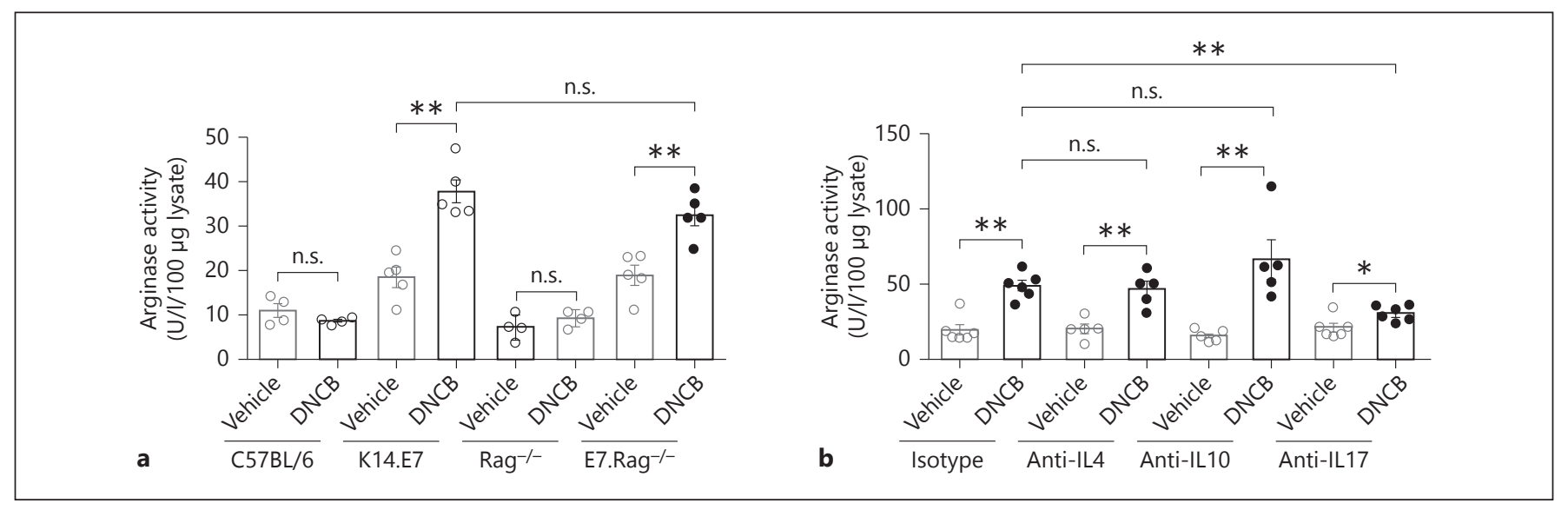

Fig. 1. IL-17A from DNCB-treated K14.E7 transgenic skin contributes to the induction of arginase in BMDMs. a C57BL/6, K14. E7, $\mathrm{Rag}^{-/-}$and E7. $\mathrm{Rag}^{-1-}$ mice were treated with vehicle or DNCB for $4 \mathrm{~h}$. Explanted skin was cultured for $24 \mathrm{~h}$ and culture supernatant was assessed for induction of BMDM arginase activity. b Arginase activity in BMDMs cultured in vehicle or DNCB-treated K14.E7 skin explant supernatants and exposed to isotype-matched antibodies or neutralising antibodies (10 ng/ml) against IL-4, IL10 or IL-17A. c Arginase activity in BMDMs cultured in supernatants from vehicle or DNCB-treated E7.IL17 ${ }^{-/-}$or E7.IL17 ${ }^{+/-}$skin explants. Data are means \pm SEM and are representative of two independent experiments, each with $4-6$ mice/group. ${ }^{*} \mathrm{p}<0.05$, $* * \mathrm{p}<0.01$. n.s. $=$ Non-significant.

scription was reduced to a much lesser extent (fig. 2c). Thus, IL-17A contributes to the induction of arginase-1 mRNA expression and arginase activity not only in BMDMs in vitro but also in K14.E7 skin following DNCB application.

IL-17A has been suggested to mediate recruitment of inflammatory macrophages [23]. Therefore, we investigated whether IL-17A mediated the induction of arginase-1 in DNCB-treated K14.E7 skin by enhancing recruitment of the $\mathrm{CD} 11 \mathrm{~b}^{+} \mathrm{Gr} 1^{\mathrm{int}} \mathrm{F} 4 / 80^{+}$subset of macrophages, which we previously showed to be the main cell population producing arginase-1 in DNCB-treated K14. E7 skin. The expected extensive infiltrate of $\mathrm{F} 4 / 80^{+}$cells in K14.E7 skin in response to DNCB application was markedly reduced in DNCB-treated E7.IL17 ${ }^{-/}$skin, demonstrating that IL-17A enhances recruitment of $\mathrm{F} 4 / 80^{+}$cells in K14.E7 skin in response to DNCB (fig. 2d). Consistent with this observation, flow-cytometric analysis showed significantly lower numbers of $\mathrm{CD}_{11} \mathrm{~b}^{+} \mathrm{F} 4 / 80^{+} \mathrm{Gr} 1^{\text {int }}$ cells in DNCB-treated E7.IL17 ${ }^{-/-}$ skin compared to K14.E7 skin (fig. 2e).

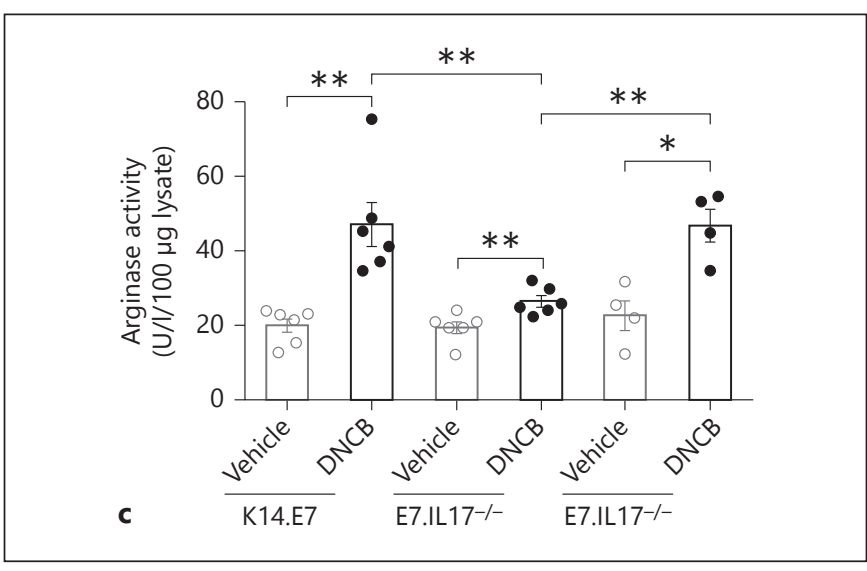

Taking these findings together, we conclude that by increasing the number of $\mathrm{CD} 11 \mathrm{~b}^{+} \mathrm{F} 4 / 80^{+} \mathrm{Gr} 1^{\text {int }}$ macrophages, IL-17A might be responsible for the increased arginase-1 mRNA expression and arginase activity in DNCB-treated K14.E7 skin.

\section{IL-17A Is Specifically Induced in DNCB-Treated}

K14.E7 Skin in the Absence of Lymphocytes

As IL-17A contributes to the enhanced induction of arginase-1 in DNCB-treated K14.E7 mouse skin, we investigated IL-17A expression in wild-type and K14.E7 mouse skin. Following DNCB application, IL-17A gene expression was significantly induced in DNCB-treated K14.E7 skin while it remained unchanged in DNCBtreated wild-type skin (fig. 3a). Additionally, DNCBtreated K14.E7 skin secreted more IL-17A into the skin explant supernatant than wild-type skin (fig. 3b). Baseline levels of IL-17A in untreated K14.E7 skin were also higher than those in C57BL/6 skin, as reported previously [24]. Thus, in addition to Th2 cytokines, IL-17A was induced in K14.E7 skin in response to DNCB. 

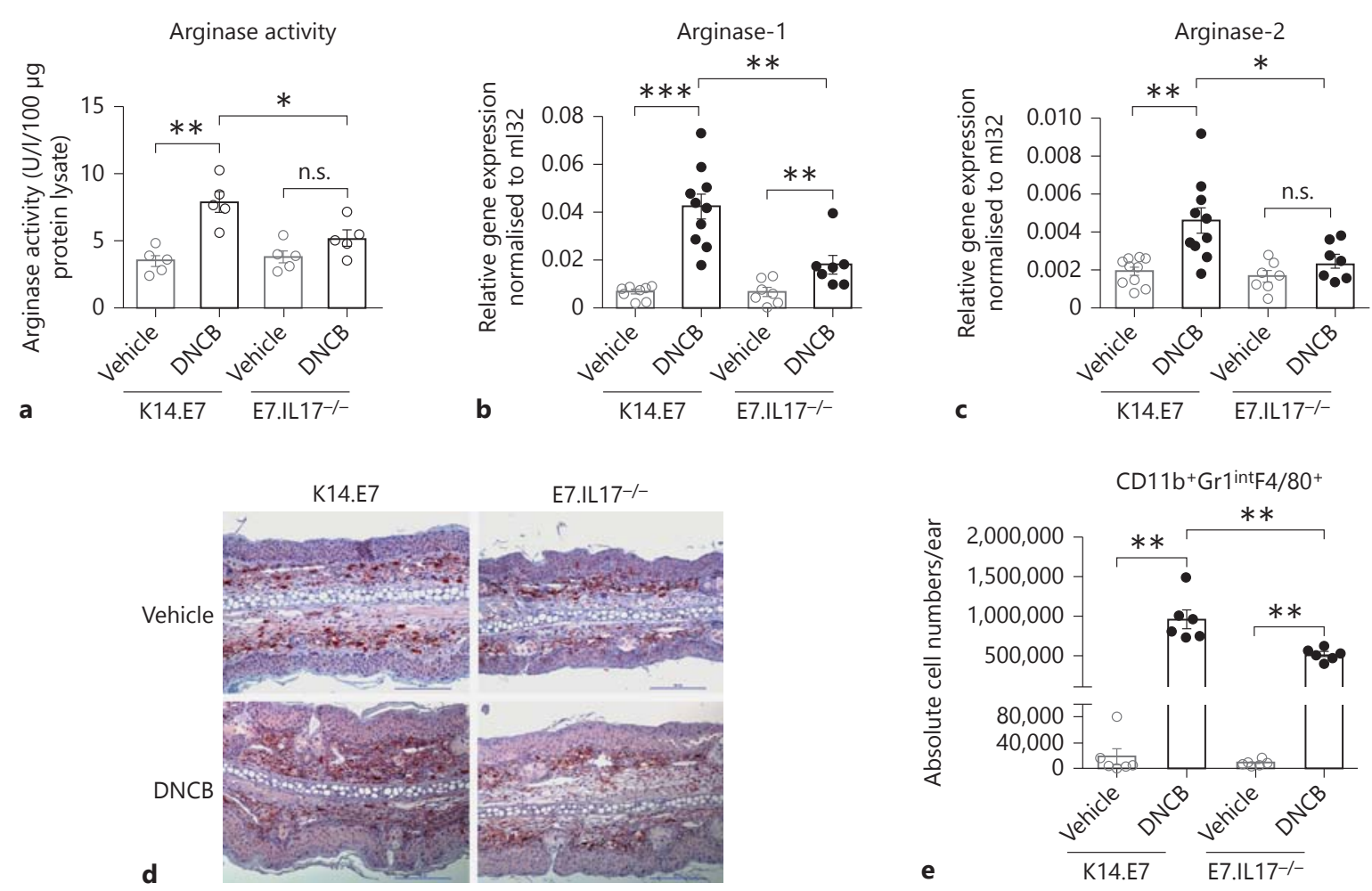

Fig. 2. IL-17A enhances recruitment of arginase-1-producing $\mathrm{CD} 11 \mathrm{~b}^{+} \mathrm{Gr} 1^{\text {int }} \mathrm{F} 4 / 80^{+}$cells to K14.E7 mouse skin following DNCB application. a Arginase activity in K14.E7 and E7.IL17 ${ }^{-/-}$mouse skin after $24 \mathrm{~h}$ of DNCB treatment. b, c Expression of arginase-1 (b) and arginase-2 (c) mRNA transcripts in K14.E7 and E7.IL17 ${ }^{-1-}$ mouse skin following DNCB application determined by real-time PCR. d Immunohistochemical analysis of $\mathrm{F} 4 / 80^{+}$macrophages in

As we previously reported that the hyperinflammatory response in K14.E7 mice exposed to DNCB is independent of lymphocyte function, we investigated the production of IL-17A in E7. $\mathrm{Rag}^{-/-}$skin. Interestingly, IL-17A mRNA expression was significantly induced by DNCB in E7. $\mathrm{Rag}^{-/-}$skin, although at a lower level than in E7 skin, but not in $\mathrm{Rag}^{-/-}$skin (fig. 3a). Consistent with this, the level of IL-17A protein released into the skin explant supernatants from both $\mathrm{Rag}^{-/-}$and E7.Rag ${ }^{-/-}$mice was undetectable by ELISA (fig. 3b), suggesting a significant contribution of lymphocytes to the enhanced IL-17A production in DNCB-treated E7 transgenic skin.

To establish the role of $\mathrm{E} 7$ protein in the induction of IL-17A, we examined the induction of IL-17A in another $\mathrm{K} 14$ transgenic mouse line (K14.hGH) and in C57BL/6 mice treated with a 10 -fold higher dose of DNCB to induce ear swelling comparable to that observed in K14.E7
K14.E7 or E7.IL17 ${ }^{-/-}$skin exposed to DNCB. Stained sections are representative of 4 mice/group, original magnification $\times 200$, scale bar $=100 \mu \mathrm{m}$. e Absolute numbers of infiltrating $\mathrm{CD} 11 \mathrm{~b}^{+} \mathrm{Gr} 1^{+} \mathrm{F} 4 / 80^{+}$ cells in K14.E7 and E7.IL17 ${ }^{-/-}$skin 1 day after DNCB treatment was determined by flow cytometry. Data are means \pm SEM and are pooled from two independent experiments, each with 4-7 mice/ group. ${ }^{*} \mathrm{p}<0.05,{ }^{* *} \mathrm{p}<0.001,{ }^{* * *} \mathrm{p}<0.0001$. n.s. $=$ Non-significant.

mouse skin exposed to a lower level of DNCB (fig. 3c). In both the K14.hGH transgenic and the C57BL/6 mouse skin, no production of IL-17A was observed. Thus, induction of IL-17A by DNCB is dependent on the expression of HPV16.E7 in skin.

Taken together, these data suggest that expression of HPV16.E7 in skin facilitates IL-17A induction in both lymphocyte and 'non-lymphocyte' immune subsets in response to DNCB.

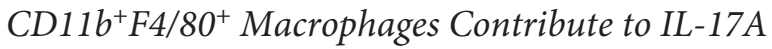

\section{Production in DNCB-Treated K14.E7 Skin}

Recent studies have reported that in addition to Th17 cells, various myeloid cells, including neutrophils [18] and macrophages [19], can produce IL-17A under inflammatory conditions. Our observation of induction of IL-17A by DNCB in E7. $\mathrm{Rag}^{-/-}$skin prompted us to test 

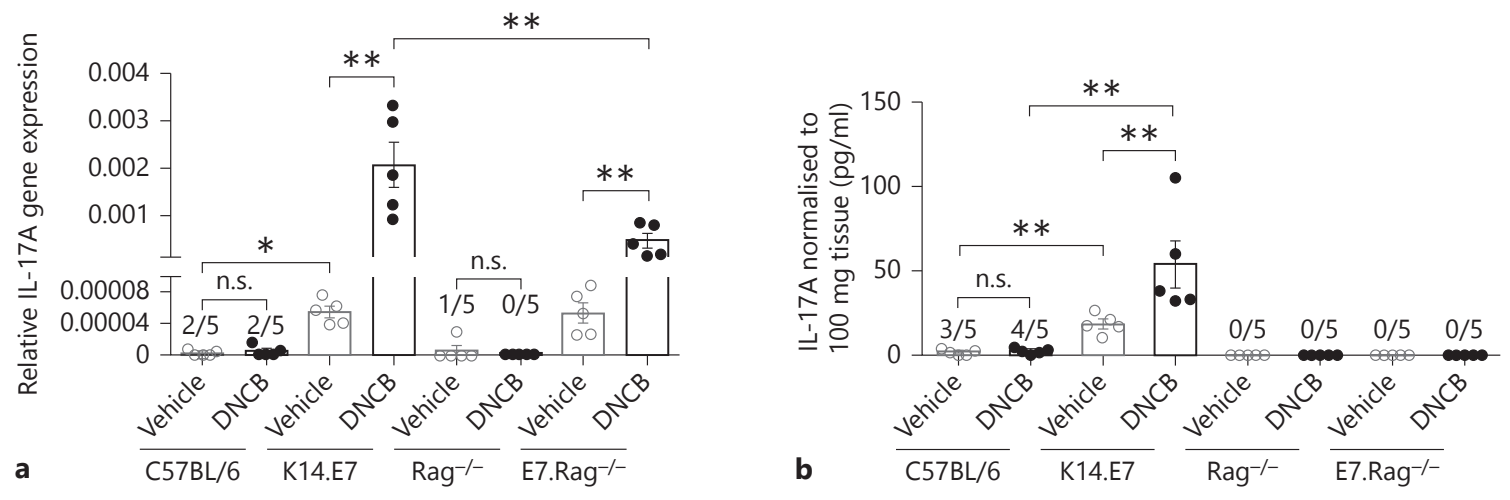

Fig. 3. IL-17A is induced by DNCB in both K14.E7 and E7. $\mathrm{Rag}^{-/-}$ transgenic skin. a, b Quantitative real-time PCR analysis of IL-17A mRNA transcripts in the skin (a) and IL-17A production (b) by ELISA in the supernatants of skin explant cultures from C57BL/6, K14.E7, $\mathrm{Rag}^{-/-}$and E7.Rag ${ }^{-/-}$mice 1 day after DNCB [1\% (w/v)] treatment or vehicle application. c Quantitative real-time PCR analysis of IL-17A mRNA transcripts in C57BL/6 treated with $10 \%$ DNCB (w/v) or in K14.HgH, K14.E7 or nor-NOHA-treated K14. E7 skin after $1 \%$ DNCB $(w / v)$ treatment. Data are means \pm SEM and represent two independent experiments, each with 4-5 animals/group. ${ }^{*} \mathrm{p}<0.05,{ }^{* *} \mathrm{p}<0.001$. n.s. $=$ Non-significant.

whether myeloid cell subsets as well as lymphocytes contributed to IL-17A production in this model. Intracellular staining confirmed expression of IL-17A in CD $45.2^{+} \mathrm{CD} 11 \mathrm{~b}^{+}$myeloid cells and $\mathrm{CD} 45.2^{+} \mathrm{CD} 11 \mathrm{~b}^{-}$cells isolated from C57BL/6, K14.E7, $\mathrm{Rag}^{-/-}$and E7. Rag ${ }^{-/-}$ mice after DNCB treatment (online suppl. fig. 1a; for all online suppl. material, see www.karger.com/doi/10.1159/ 000374115). As expected, flow-cytometric analysis showed a significant increase in the percentage (online suppl. fig. 1b) as well as absolute number of IL-17A

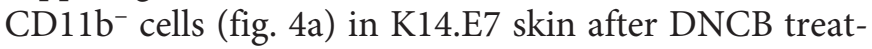
ment, whereas the number of these cells remained unchanged in E7. Rag ${ }^{-/-}$, C57BL/6 and $\mathrm{Rag}^{-/-}$mouse skin. Thus, while in K14.E7 skin lymphocytes induced a significant amount of IL-17A after DNCB treatment, in both K14.E7 and E7.Rag ${ }^{-/}$mice there was an increase in the proportion (online suppl. fig. 1c) and number of IL-17A ${ }^{+}$

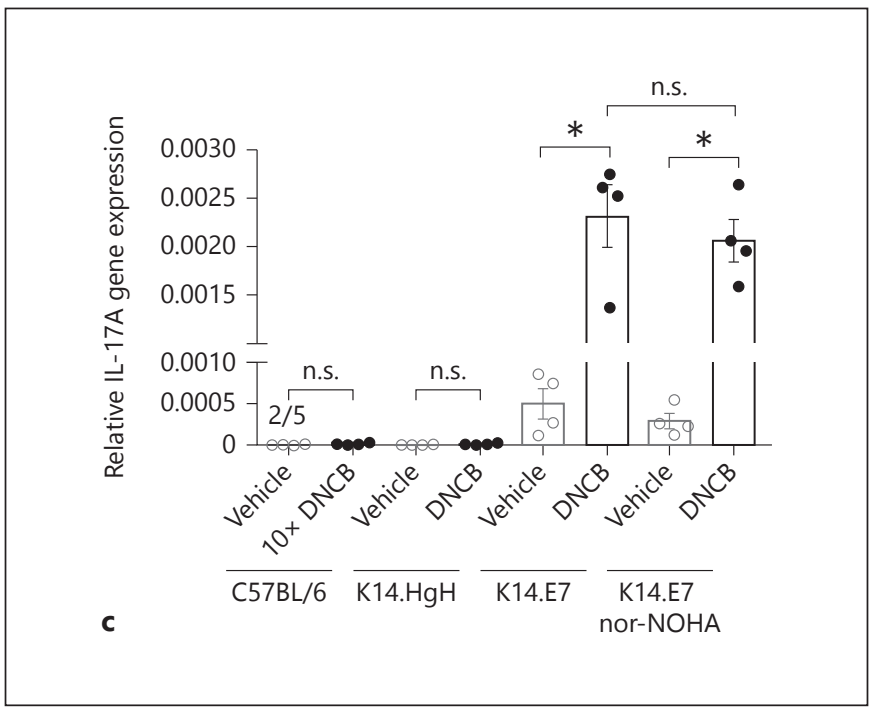

$\mathrm{CD}_{11 \mathrm{~b}}{ }^{+}$cells compared to $\mathrm{C} 57 \mathrm{BL} / 6$ and $\mathrm{Rag}^{-/-}$mice (fig. 4b). Also, DNCB-treated K14.E7 mice had approximately 6 -fold more IL- $17 \mathrm{~A}^{+} \mathrm{CD} 11 \mathrm{~b}^{+}$cells $(12,026 \pm 1,234$ cells/ear, mean \pm SEM) than $\mathrm{IL}_{-17 \mathrm{~A}^{+}} \mathrm{CD} 11 \mathrm{~b}^{-}$cells $(1,925 \pm 354$ cells/ear, mean \pm SEM $)$, indicating that $\mathrm{CD}_{11 \mathrm{~b}}{ }^{+}$myeloid cells were also a major source of IL-17A in these mice (fig. 4a, b). To further indentify which myeloid cell subsets produce IL-17A in DNCB-treated K14. $\mathrm{E} 7$ and $\mathrm{E} 7 . \mathrm{Rag}^{--}$mice, we analysed the expression of IL$17 \mathrm{~A}$ in macrophage $\left(\mathrm{F} 4 / 80^{+}\right)$, neutrophil $\left(\mathrm{Gr} 1^{\mathrm{hi}}\right)$ and dendritic cell $\left(\mathrm{CD} 11 \mathrm{c}^{+} \mathrm{MHCII}^{+}\right)$fractions of the $\mathrm{CD} 11 \mathrm{~b}^{+}$cell population. F4/80 $0^{+}$macrophages from both K14.E7 and E7. $\mathrm{Rag}^{-/-}$skin, but not from their counterpart controls (C57BL/6 and $\mathrm{Rag}^{-1-}$ ), showed increased production of IL-17A after DNCB treatment (fig. 4c, d). Furthermore, the average number of $\mathrm{IL}-17 \mathrm{~A}^{+} \mathrm{CD} 11 \mathrm{~b}^{+} \mathrm{F} 4 / 80^{+}$cells $(12,487 \pm 2,810$ cells/ear, mean \pm SEM $)$ in DNCB-treated 


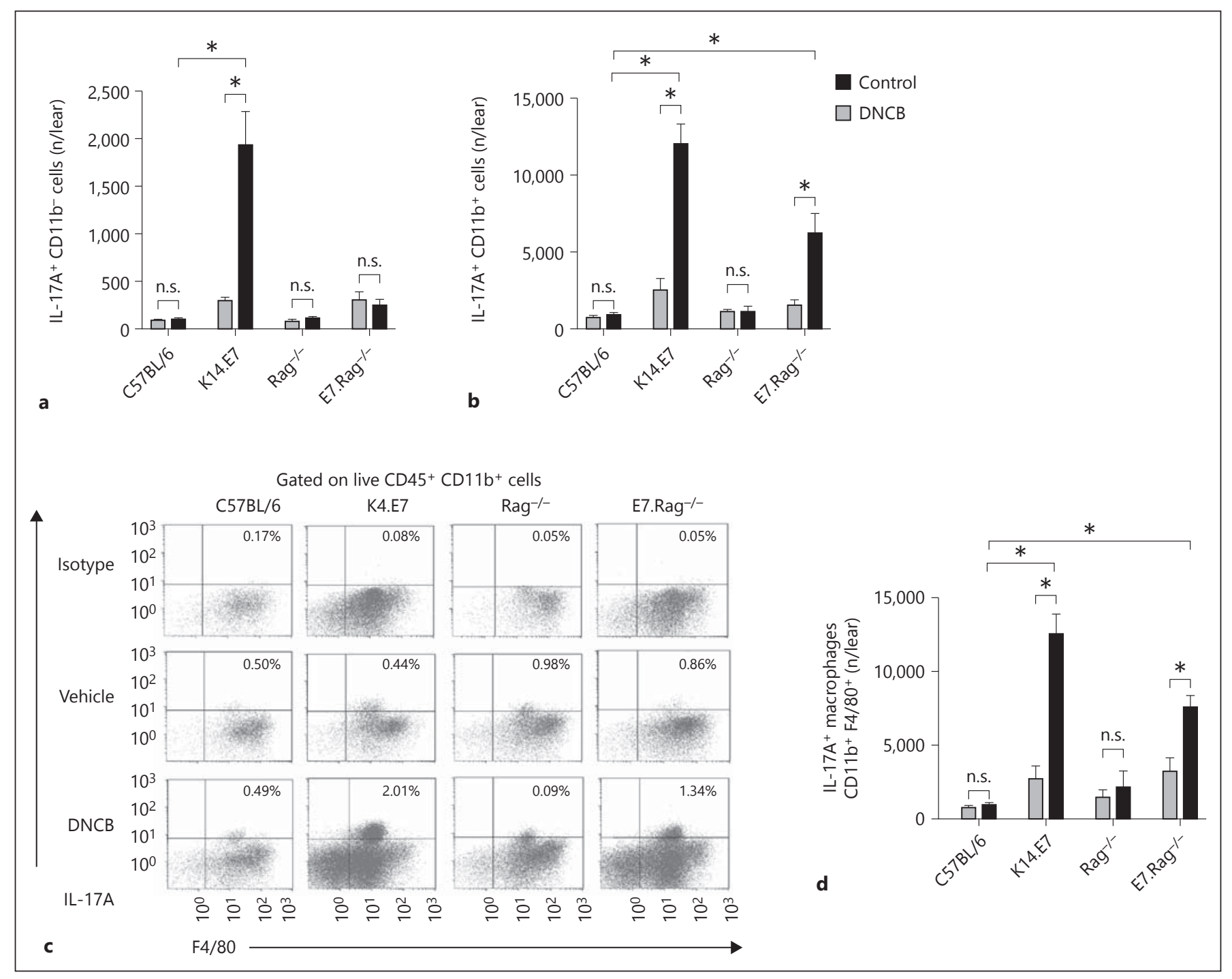

Fig. 4. DNCB-induced IL-17A is mostly produced by $\mathrm{CD} 11 \mathrm{~b}^{+} \mathrm{F} 4 / 80^{+}$macrophages. C57BL/6, K14.E7, $\mathrm{Rag}^{-/-}$and E7. $\mathrm{Rag}^{-/-}$mice were treated with vehicle or DNCB, and after $24 \mathrm{~h}$ cells were isolated from ear skin tissues and stained for IL-17A. $\mathbf{a}, \mathbf{b}, \mathbf{d}$ Absolute numbers of IL17A ${ }^{+} \mathrm{CD} 11 \mathrm{~b}^{-}(\mathbf{a}), \mathrm{IL}-17 \mathrm{~A}^{+} \mathrm{CD} 11 \mathrm{~b}^{+}$

K14.E7 skin was 6 -fold greater than that of IL-17A CD11 $\mathrm{b}^{-}$cells $(1,925 \pm 354$ cells/ear, mean \pm SEM $)$, confirming that IL-17A-producing macrophages markedly outnumber IL-17A-producing lymphocytes.

Interestingly, neither neutrophils nor dendritic cells showed staining for IL-17A in K14.E7 mice after DNCB treatment (online suppl. fig. $1 \mathrm{~d}$ ). Thus, $\mathrm{CD} 11 \mathrm{~b}^{+} \mathrm{F} 4 / 80^{+}$ macrophages were major contributors of IL-17A induction in DNCB-treated K14.E7 skin, and this increased production occurred in the absence of $\mathrm{T}$ and $\mathrm{B}$ lymphocytes. (b) and $\mathrm{IL}-17 \mathrm{~A}^{+} \mathrm{CD} 11 \mathrm{~b}^{+} \mathrm{F} 4 / 80^{+}$(d) cells. c Representative dot plots pre-gated on viable $\mathrm{CD} 45.2^{+} \mathrm{CD} 11 \mathrm{~b}^{+}$cells and stained with F4/80 and IL-17A. Data are means \pm SEM and represent two independent experiments of 4 animals/experiment. ${ }^{*} \mathrm{p}<0.05$. n.s. $=$ Non-significant.

\section{Suppression of IL-17A or Arginase-1 Attenuates the DNCB-Induced Inflammation in K14.E7 Skin}

To address whether IL-17A expression is sufficient to trigger the enhanced acute inflammation in K14.E7 and E7. Rag $^{-/-}$skin, we applied DNCB to E7.IL17 ${ }^{-/-}$or IL-17A neutralising antibody-treated K14.E7 and E7. $\mathrm{Rag}^{-1-}$ mice. Pre-treatment of mice with IL-17A neutralising antibody, when compared to isotype control antibody, caused a significant reduction in ear swelling (fig. 5a). Further histological examination also showed a significant reduction in ear thickness and the number of infiltrating leucocytes 


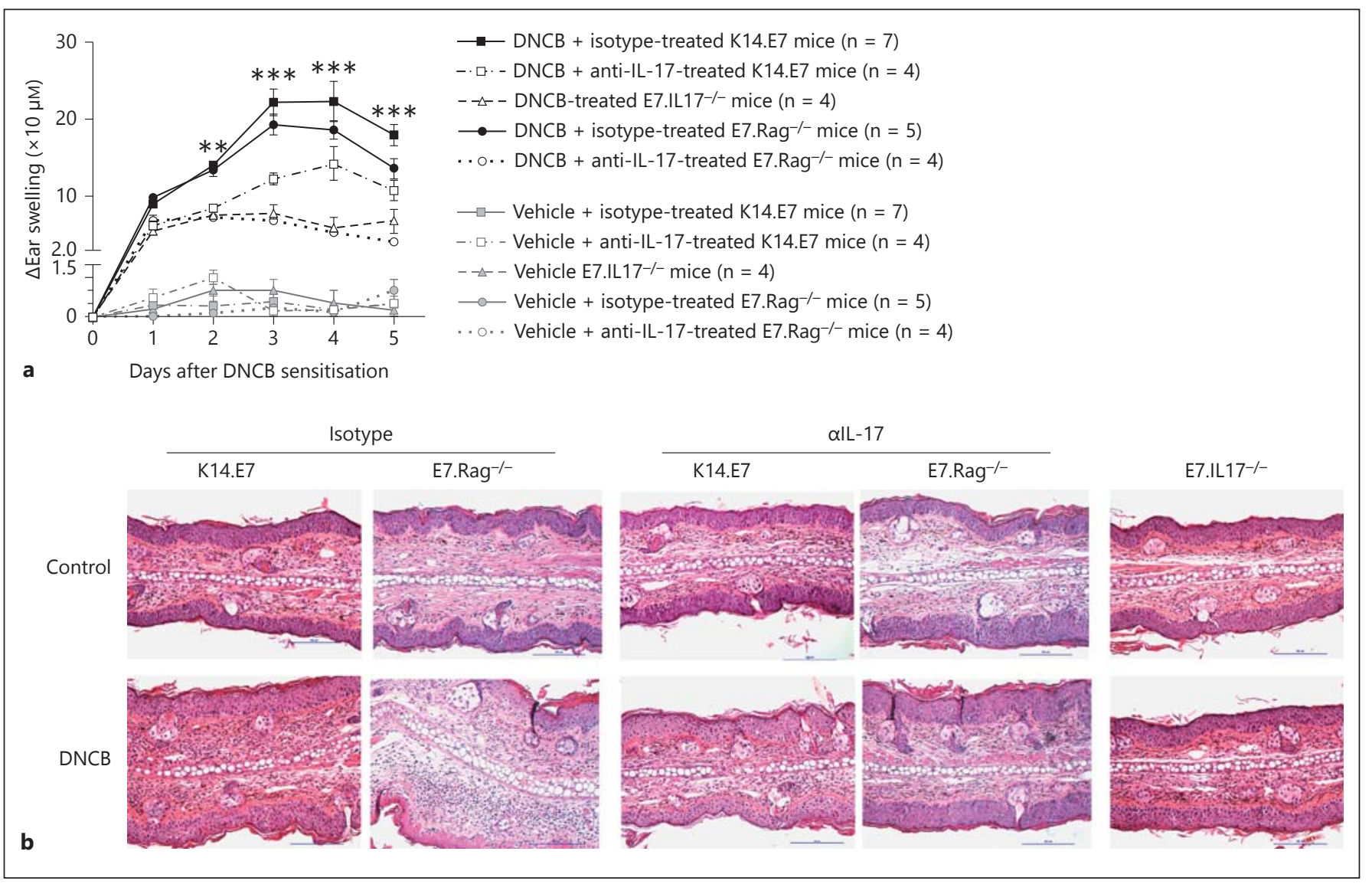

Fig. 5. IL-17A promotes ear swelling induced by DNCB in K14.E7 skin. a Ear swelling of isotype or anti-IL-17A neutralising antibody-treated K14.E7 and E7.Rag ${ }^{-/-}$or E7.IL17 ${ }^{-/-}$mice following DNCB application. Data are means \pm SEM and representative of 2 independent experiments, each with $4-7$ animals/group. ${ }^{*} \mathrm{p}<0.05$,

within the dermis of E7.IL17 ${ }^{-/}$mice or K14.E7 and E7. $\mathrm{Rag}^{-/-}$mice pre-treated with anti-IL-17A neutralising antibody, as compared with K14.E7 and E7. $\mathrm{Rag}^{-1-}$ mice, respectively, 1 day after DNCB treatment (fig. 5b).

\section{IL-17A and Arginase-1 Mediate Enhanced}

Recruitment of Neutrophils in DNCB-Treated K14.E7

Skin via CXCL1 and CXCL5 Production

Neutralisation of IL-17A in K14.E7 mice reduced the DNCB-induced ear swelling on day 5 after treatment to a greater extent than suppression of arginase activity (fig. 6). As IL-17A was shown to promote arginase production, we assessed whether simultaneous inhibition of arginase and IL-17A suppressed ear swelling to a greater extent compared to blockade of IL-17 A alone. If both IL-17A and arginase were inhibited, ear swelling levels were similar to mice in which only IL-17A was depeleted (fig. 6).
${ }^{* *} \mathrm{p}<0.01,{ }^{* * *} \mathrm{p}<0.001$. n.s. $=$ Non-significant. $\mathbf{b}$ Histological analysis of isotype antibody or anti-IL-17A neutralising antibodytreated K14.E7 and E7.Rag ${ }^{-/-}$skin or E7.IL17 ${ }^{-/-}$skin (representative of 4 mice/group). HE. Original magnification $\times 200$. Scale bar $=100 \mu \mathrm{m}$.

We have demonstrated that the hyperinflammatory response in K14.E7 skin is manifested by increased recruitment of myeloid cells, particularly neutrophils, which account for a significant proportion of total infiltrating myeloid cells (online suppl. fig. 2). Deficiency in IL-17A or blockade of arginase-1 production significantly reduced the number of neutrophils $\left(\mathrm{CD} 11 \mathrm{~b}^{+} \mathrm{Gr} 1^{\text {hi }}\right.$ cells) but not of other cell types in DNCB-treated K14.E7 skin (fig. $7 \mathrm{a}-\mathrm{c}$ ). Recruitment of neutrophils is driven by chemokines, including CXCL1, CXCL2 and CXCL5. Chemokine production is highly elevated in K14.E7 skin following DNCB treatment. Conversely, the expression level of CXCL1 and CXCL5, but not CXCL2, was significantly reduced in E7.IL17 $7^{-/}$skin and in arginase inhibitor-treated K14.E7 skin, suggesting that both IL-17A and arginase were required for the induction of these chemokines (fig. 7d-f). 


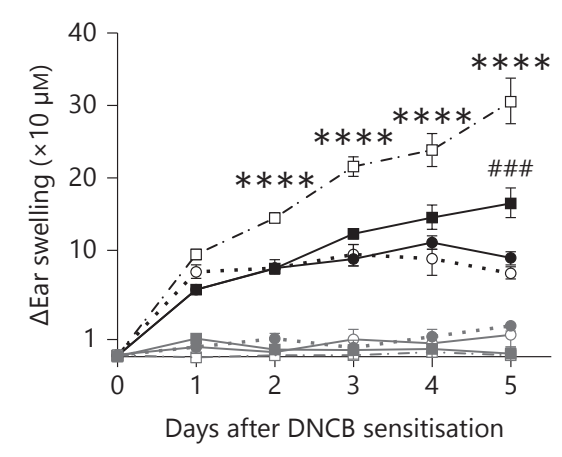

$\longrightarrow$ DNCB + PBS-treated K14.E7

-. - - DNCB + nor-NOHA-treated K14.E7

$\longrightarrow$ DNCB + PBS-treated E7.IL17-/-

. . . D DNCB + nor-NOHA-treated E7.IL17-/-

$\longrightarrow$ Vehicle + PBS-treated K14.E7

- - - - Vehicle + nor-NOHA-treated K14.E7

$\longrightarrow$ DNCB + PBS-treated E7.IL17-/-

$\because \circ \cdot$ DNCB + nor-NOHA-treated E7.IL17-/-

Fig. 6. IL-17A and arginase blockade cause comparable suppression of ear swelling in DNCB-treated K14.E7 mouse skin. Ear swelling of K14.E7 and E7.IL17 ${ }^{-/-}$mice treated with PBS or 500 $\mu \mathrm{g}$ of nor-NOHA/mouse 1 day before DNCB or vehicle application for 5 days. Data are means \pm SEM and representative of 2 independent experiments. ${ }^{* * *} \mathrm{p}<0.001$ (DNCB- and PBS-treated K14.E7 skin vs. other treatment groups), \#\# $\mathrm{p}<0.001$ (DNCBand nor-NOH-treated K14.E7 skin vs. DNCB-treated E7.IL17 ${ }^{-/-}$ or DNCB-treated and IL-17A-blocked K14.E7 group).

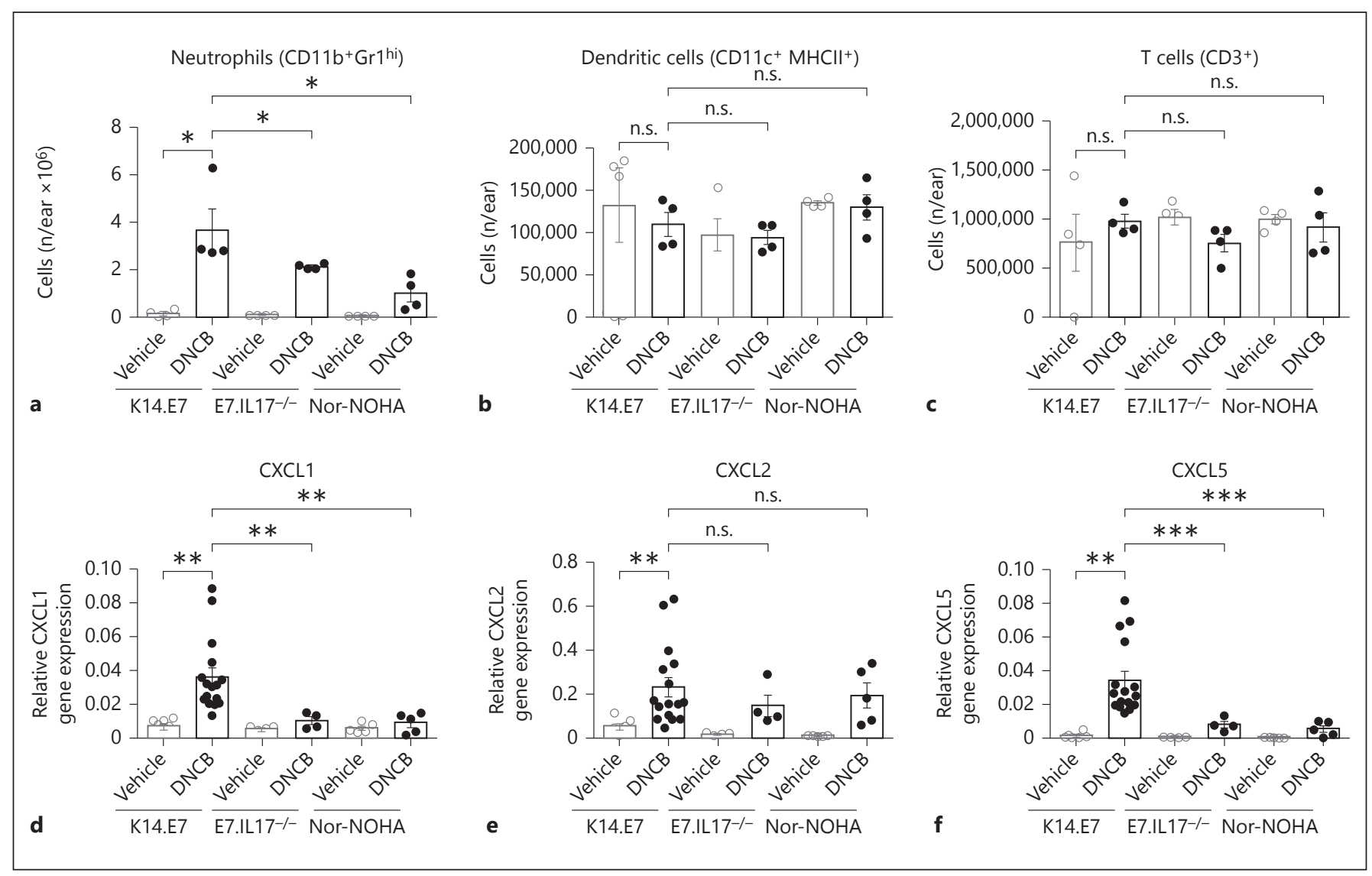

Fig. 7. IL-17A and arginase induce chemokine production and neutrophil recruitment in DNCB-treated K14.E7 mouse skin (a-c). Absolute numbers of neutrophils $\left(\mathrm{CD}_{11} \mathrm{~b}^{+} \mathrm{Gr} 1^{\mathrm{hi}} ; \mathbf{a}\right)$, dendritic cells $\left(\mathrm{CD}_{11 \mathrm{c}^{+}} \mathrm{MHCII}^{+} ; \mathbf{b}\right)$ and $\mathrm{T}$ cells $\left(\mathrm{CD}^{+} ; \mathbf{c}\right)$ in K14.E7 mice, E7. $\mathrm{IL}^{-/-}$mice and arginase inhibitor (nor-NOHA)-treated K14.E7 mice 1 day after DNCB application were determined by flow cytometry. d-f Quantitative real-time PCR analysis of CXCL1 (d), CXCL2 (e) and CXCL5 (f) transcripts in these mice. Data are means \pm SEM and are pooled from 2 independent experiments ( $\geq 4$ mice/group). ${ }^{*} \mathrm{p}<0.05,{ }^{* *} \mathrm{p}<0.01,{ }^{* * *} \mathrm{p}<0.001$. n.s. $=$ Non-significant. 
Taken together, our data show that IL-17A contributed to the enhanced production of arginase- 1 and that IL-17A together with arginase-1 contributed to DNCBinduced hyperinflammatory responses in HPV16.E7-expressing skin, possibly by promoting the production of CXCL1 and CXCL5 chemokine-mediated recruitment of neutrophils.

\section{Discussion}

Here, we show that induction of IL-17A contributes to a significantly enhanced chemokine-mediated recruitment of neutrophils and arginase-1-producing macrophages in skin expressing the E7 protein of HPV16 treated with DNCB when compared with non-transgenic skin similarly treated with DNCB. We have previously demonstrated that HPV16.E7-expressing skin exposed to DNCB develops a hyperinflammatory response, which is associated with recruitment of myeloid cells producing arginase- 1 , and that arginase- 1 activity contributes to the enhanced inflammation [11]. Here, ex vivo skin explant culture supernatants induced enhanced arginase activity in BMDMs in immunocompetent and $\mathrm{Rag}^{-/-}$mice, confirming that arginase-1 induction in K14.E7 skin exposed to DNCB was dependent on innate immune cells rather than $\mathrm{T}$ and $\mathrm{B}$ lymphocytes [11].

Th2 cytokines, including IL-4 and IL-10, which were described as potent inducers of arginase- 1 in macrophages [12] as well as important regulators of cutaneous inflammation [14], were found to be induced in K14.E7 skin but not in wild-type C57BL/6 skin, suggesting a possible involvement of these cytokines in arginase- 1 regulation. Consistent with previous reports $[13,25]$, we found that BMDMs treated with IL-4 and LPS significantly induced arginase activity and that arginase- 1 induction was completely abrogated in the presence of anti-IL- 4 or antiIL-10 neutralising antibody (online suppl. fig. 3). However, IL-4 and IL-10 blockade failed to reduce arginase-1 activity in BMDMs treated with skin explant supernatant from DNCB-treated K14.E7 skin. Furthermore, the induction of Th2 cytokines IL- 4 and IL-10 was abrogated in DNCB-treated E7.Rag ${ }^{-/-}$skin (online suppl. fig. 4), arguing against a role for these cytokines in arginase-1 induction in K14.E7 skin since the enhanced production of arginase- 1 also occurred in the absence of lymphocytes.

Our observation that blockade of IL-17A caused a significant reduction in arginase- 1 is consistent with a recent study which suggested that IL-17A indirectly mediates arginase-1 production in macrophages via the induction of cyclooxygenase- 2 production by HeLa, a human cervical cancer cell line [17]. Moreover, IL-17A has been shown to mediate arginase-1 induction by promoting infiltration of inflammatory monocytes to the site of inflammation [26]. In support of this, blockade of IL-17A in DNCB-treated K14.E7 skin significantly decreased the number of arginase-producing $\mathrm{CD} 11 \mathrm{~b}^{+} \mathrm{Gr} 1^{\text {int }} \mathrm{F} 4 / 80^{+}$ cells. IL-17A might act as an upstream enhancer of local arginase activity by enhancing recruitment of inflammatory macrophages.

IL-17A and arginase-1 were not induced in the hyperinflammation established in non-transgenic skin exposed to $10 \% \mathrm{DNCB}$, suggesting the involvement of HPV16.E7 oncoprotein or HPV16.E7-induced hyperproliferative epithelium in the induction of these molecules. A recent study in our laboratory suggested that expression of HPV16.E7 oncoprotein leads to elevated production of IL-17A in the skin of K14.E7 mice and hyperplastic cervical tissue [24]. To date, there is no evidence in the literature that HPV16.E7 protein can directly affect the transcription of arginase. Furthermore, the E7-associated mechanisms that are responsible for IL-17A or arginase-1 induction in association with DNCB treatment remain unknown. It is speculated that E7 oncoprotein expression interacts with DNCB as an inflammasome activator, which subsequently drives the secretion of active IL- $1 \beta$ and IL- 6 [27]. These inflammasome-derived cytokines have been shown to promote IL-17A production not only by Th17 but also by 'non- $T$ cell', innate lymphoid cells [28]. In support of this hypothesis, we previously demonstrated the induction of both IL-1 $\beta$ and IL-6 in K14.E7 skin but not in non-transgenic skin following DNCB treatment.

IL-17A production was produced by $\mathrm{CD} 11 \mathrm{~b}^{+} \mathrm{F} 4 / 80^{+}$ macrophages in DNCB-treated E7. Rag ${ }^{-/-}$skin in which Th17 and $\gamma \delta$ T cells are absent, confirming the findings of others that lymphocyte subsets are not exclusive sources of IL-17A $[19,28]$. The proportion of IL-17A-producing macrophages was significantly reduced in $\mathrm{E} 7 . \mathrm{Rag}^{-1-}$ skin compared to K14.E7 skin, suggesting that lymphocytes contributed significantly to the induction of IL-17A in these cells. However, this subset appeared to be a major producer of IL-17A in K14.E7 skin, as IL-17A ${ }^{+}$macrophages markedly outnumber IL-17A ${ }^{+} \mathrm{T}$ cells in K14.E7 skin. Thus, it is possible that IL-17A-secreting macrophages might stimulate themselves in an autocrine manner leading to enhanced production of arginase-1. Alternatively, IL-17A and arginase- 1 are produced by two different subsets of $\mathrm{CD} 11 \mathrm{~b}^{+} \mathrm{Gr} 1^{\mathrm{int}} \mathrm{F} 4 / 80^{+}$cells. Indeed, further characterisation of the IL-17A-producing subset showed that they do not express MHCII, while arginase-1-producing 
cells express MHCII (data not shown). Further, suppression of IL-17A in K14.E7 mice could not completely abrogate arginase- 1 induction, suggesting that IL-17A is not the only factor promoting arginase- 1 induction.

IL-17A neutralisation in K14.E7 skin as well as E7. $\mathrm{Rag}^{-/-}$resulted in reduced DNCB-induced ear swelling, suggesting that macrophage-derived IL-17A contributed to the hyperinflammation induced by DNCB in K14.E7 skin. Although Th17 and other lymphocyte subsets are regarded as primary sources of IL-17A and have been implicated as effector cells of cutaneous inflammation, our findings are in agreement with a recent study that shows alveolar macrophages as a source of IL-17A, which mediated allergic lung inflammation in a murine model of asthma [19]. Furthermore, innate lymphoid cells, which are present in DNCB-treated E7. $\mathrm{Rag}^{-1-}$ animals, might also be implicated in the induction of IL-17A and DNCBinduced hyperinflammation. In a recent study using a mouse model of obesity-induced airway hyperreactivity, secretion of IL- $1 \beta$ by activation of NLRP3 inflammasomes was shown to promote IL-17A production in type 3 innate lymphoid cells, leading to the development of airway hyperresponsiveness [28].

The mechanisms driving the initiation of inflammation in this model remained unidentified so far, as the induction of ear swelling, measured 1 day after DNCB application, did not change regardless of whether IL-17A or arginase was suppressed. However, our data clearly show that IL-17A and arginase are significantly required for the ongoing hyperinflammation in K14.E7 after day 2. Simultaneous blockade of both IL-17A and arginase activity did not further suppress the ear swelling response in DNCB-treated K14.E7 compared to either blockade alone. In addition, suppression of arginase activity did not reduce IL-17A production in DNCB-treated K14.E7 skin, further confirming that arginase-1 and IL-17A act in the same pathway and IL-17A is likely to be an upstream mediator of arginase- 1 .

DNCB-induced hyperinflammation in K14.E7 skin is manifested by the infiltration of myeloid cells, particularly neutrophils. Blockade of either IL-17A or arginase resulted in a decrease in the number of infiltrating neutrophils, thereby reducing neutrophilic inflammation caused by DNCB in K14.E7 skin. CXCL1, CXCL2 and CXCL5, which signal through CXCR2 receptors, are the most potent neutrophil chemo-attractants and appear to selectively promote neutrophil infiltration [20]. These chemokines were all induced in K14.E7 skin after DNCB treatment, and IL-17A deficiency and suppression of arginase- 1 in K14.E7 skin significantly reduced the expression of CXCL1 and
CXCL5, suggesting that CXCL1 and CXCL5 are important mediators for IL-17A and arginase to promote hyperinflammation in K14.E7 skin. Our findings are supported by previous studies showing that IL-17A promotes neutrophil infiltration via CXCL1 [29] or CXCL5 [30] induction during acute inflammatory responses. Further, arginase-specific inhibitor treatment significantly ameliorated pulmonary inflammation and airway fibrosis in guinea pigs repeatedly exposed to LPS. The alleviated inflammation in these animals was concomitant with decreased neutrophil infiltration [31]. However, whether IL-17A has a direct role in neutrophil recruitment and chemokine induction or acts through arginase-1 remains unknown.

In summary, the present study shows that DNCB application to HPV16.E7-expressing skin results in acute hyperinflammation through a previously undescribed pathway which involves IL-17A, an enhancer of arginase- 1 production. This study also identifies the E7-associated proinflammatory roles for IL-17A and arginase-1 that might be considered potential targets to stimulate innate immunity, which is speculated to support antigenspecific immune therapies for the treatment of HPV-associated diseases.

\section{Acknowledgements}

This work was supported by grants from the NIH (5U01CA141583), National Health and Medical Research Council of Australia (569938) to I.H.F. I.H.F. was a recipient of a Queensland Government Premiers Fellowship. T.L.S. is a recipient of a University of Queensland fellowship for international students. We would like to thank the staff of the Biological Research Facility at the Translational Research Institute for technical assistance and animal care. We also acknowledge Lilly Research Laboratories for providing anti-IL-17A neutralising and isotype-matched control antibodies.

\section{Disclosure Statement}

The authors state no conflict of interest.

\begin{tabular}{|c|c|}
\hline References & $\begin{array}{l}\text { - Stanley MA: Epithelial cell responses to infec- } \\
\text { tion with human papillomavirus. Clin Micro- } \\
\text { biol Rev 2012;25:215-222. } \\
\text { B } \\
\text { Bhat P, Mattarollo SR, Gosmann C, Frazer IH, } \\
\text { Leggatt GR: Regulation of immune responses } \\
\text { to HPV infection and during HPV-directed } \\
\text { immunotherapy. Immunol Rev 2011;239:85- } \\
98 \text {. } \\
3 \text { Borchers A, Braspenning J, Meijer J, Osen W, } \\
\text { Gissmann L, Jochmus I: E7-specific cytotoxic } \\
\text { T cell tolerance in HPV-transgenic mice. } \\
\text { Arch Virol 1999;144:1539-1556. }\end{array}$ \\
\hline
\end{tabular}


4 Durst M, Glitz D, Schneider A, zur Hausen H: Human papillomavirus type 16 (HPV 16) gene expression and DNA replication in cervical neoplasia: analysis by in situ hybridization. Virology 1992;189:132-140.

5 Frazer IH, Leggatt GR, Mattarollo SR: Prevention and treatment of papillomavirus-related cancers through immunization. Annu Rev Immunol 2011;29:111-138.

-6 Mattarollo SR, Rahimpour A, Choyce A, Godfrey DI, Leggatt GR, Frazer IH: Invariant NKT cells in hyperplastic skin induce a local immune suppressive environment by IFNgamma production. J Immunol 2010;184: $1242-1250$.

7 Mittal D, Kassianos AJ, Tran LS, Bergot AS, Gosmann C, Hofmann J, Blumenthal A, Leggatt GR, Frazer IH: Indoleamine 2,3-dioxygenase activity contributes to local immune suppression in the skin expressing human papillomavirus oncoprotein E7. J Invest Dermatol 2013;133:2686-2694.

8 Georgala S, Danopoulou I, Katsarou A: Dinitrochlorobenzene treatment of condylomata acuminata. Australas J Dermatol 1989;30: 103-105.

-9 Belij S, Popov A, Zolotarevski L, Mirkov I, Djokic J, Kataranovski D, Kataranovski M: Systemic immunomodulatory effects of topical dinitrochlorobenzene (DNCB) in rats. Activity of peripheral blood polymorphonuclear cells. Environ Toxicol Pharmacol 2012;33:168-180.

10 Black HS, Castrow FF 2nd, Gerguis J: The mutagenicity of dinitrochlorobenzene. Arch Dermatol 1985;121:348-349.

-11 Tran le S, Bergot AS, Mattarollo SR, Mittal D, Frazer IH: Human papillomavirus e7 oncoprotein transgenic skin develops an enhanced inflammatory response to 2,4-dinitrochlorobenzene by an arginase-1-dependent mechanism. J Invest Dermatol 2014;134:2438-2446.

12 Pauleau AL, Rutschman R, Lang R, Pernis A, Watowich SS, Murray PJ: Enhancer-mediated control of macrophage-specific arginase I expression. J Immunol 2004;172:7565-7573.

13 Modolell M, Corraliza IM, Link F, Soler G, Eichmann K: Reciprocal regulation of the nitric oxide synthase/arginase balance in mouse bone marrow-derived macrophages by $\mathrm{TH} 1$ and TH2 cytokines. Eur J Immunol 1995;25: 1101-1104.
14 Masuoka M, Shiraishi H, Ohta S, Suzuki S, Arima K, Aoki S, Toda S, Inagaki N, Kurihara Y, Hayashida S, Takeuchi S, Koike K, Ono J, Noshiro H, Furue M, Conway SJ, Narisawa Y, Izuhara K: Periostin promotes chronic allergic inflammation in response to Th2 cytokines. J Clin Invest 2012;122:2590-2600.

15 Sousa LM, Carneiro MB, Resende ME, Martins LS, Dos Santos LM, Vaz LG, Mello PS, Mosser DM, Oliveira MA, Vieira LQ: Neutrophils have a protective role during early stages of Leishmania amazonensis infection in BALB/c mice. Parasite Immunol 2014;36:1331.

16 Usui F, Kimura H, Ohshiro T, Tatsumi K, Kawashima A, Nishiyama A, Iwakura Y, Ishibashi S, Takahashi M: Interleukin-17 deficiency reduced vascular inflammation and development of atherosclerosis in Western diet-induced apoE-deficient mice. Biochem Biophys Res Commun 2012;420:72-77.

17 Li Q, Liu L, Zhang Q, Liu S, Ge D, You Z: Interleukin-17 indirectly promotes M2 macrophage differentiation through stimulation of COX-2/PGE2 pathway in the cancer cells. Cancer Res Treat 2014;46:297-306.

18 Li L, Huang L, Vergis AL, Ye H, Bajwa A, Narayan $\mathrm{V}$, Strieter RM, Rosin DL, Okusa MD: IL-17 produced by neutrophils regulates IFNgamma-mediated neutrophil migration in mouse kidney ischemia-reperfusion injury. J Clin Invest 2010;120:331-342.

19 Song C, Luo L, Lei Z, Li B, Liang Z, Liu G, Li D, Zhang G, Huang B, Feng ZH: IL-17-producing alveolar macrophages mediate allergic lung inflammation related to asthma. J Immunol 2008;181:6117-6124.

20 Mizutani N, Nabe T, Yoshino S: IL-17A promotes the exacerbation of IL-33-induced airway hyperresponsiveness by enhancing neutrophilic inflammation via CXCR2 signaling in mice. J Immunol 2014;192:1372-1384.

21 Narayan S, Choyce A, Linedale R, Saunders NA, Dahler A, Chan E, Fernando GJ, Frazer IH, Leggatt GR: Epithelial expression of human papillomavirus type $16 \mathrm{E} 7$ protein results in peripheral CD8 T-cell suppression mediated by $\mathrm{CD} 4+\mathrm{CD} 25+\mathrm{T}$ cells. Eur J Immunol 2009;39:481-490.

22 Chang CI, Zoghi B, Liao JC, Kuo L: The involvement of tyrosine kinases, cyclic AMP/ protein kinase $\mathrm{A}$, and $\mathrm{p} 38$ mitogen-activated protein kinase in IL-13-mediated arginase I induction in macrophages: its implications in IL-13-inhibited nitric oxide production. J Immunol 2000;165:2134-2141.
23 Barin JG, Baldeviano GC, Talor MV, Wu L, Ong S, Quader F, Chen P, Zheng D, Caturegli P, Rose NR, Cihakova D: Macrophages participate in IL-17-mediated inflammation. Eur J Immunol 2012;42:726-736.

24 Gosmann C, Mattarollo SR, Bridge JA, Frazer IH, Blumenthal A: IL-17 suppresses immune effector functions in human papillomavirusassociated epithelial hyperplasia. J Immunol 2014;193:2248-2257.

25 Menzies FM, Henriquez FL, Alexander J, Roberts CW: Selective inhibition and augmentation of alternative macrophage activation by progesterone. Immunology 2011;134: 281-291.

26 Butcher MJ, Gjurich BN, Phillips T, Galkina EV: The IL-17A/IL-17RA axis plays a proatherogenic role via the regulation of aortic myeloid cell recruitment. Circ Res 2012;110: 675-687.

27 Watanabe H, Gaide O, Petrilli V, Martinon F, Contassot E, Roques S, Kummer JA, Tschopp J, French LE: Activation of the IL-1beta-processing inflammasome is involved in contact hypersensitivity. J Invest Dermatol 2007;127: 1956-1963.

28 Kim HY, Lee HJ, Chang YJ, Pichavant M, Shore SA, Fitzgerald KA, Iwakura Y, Israel E, Bolger K, Faul J, DeKruyff RH, Umetsu DT: Interleukin-17-producing innate lymphoid cells and the NLRP3 inflammasome facilitate obesity-associated airway hyperreactivity. Nat Med 2014;20:54-61.

29 Brackett CM, Muhitch JB, Evans SS, Gollnick SO: IL-17 promotes neutrophil entry into tumor-draining lymph nodes following induction of sterile inflammation. J Immunol 2013; 191:4348-4357.

30 Liu Y, Mei J, Gonzales L, Yang G, Dai N, Wang P, Zhang P, Favara M, Malcolm KC, Guttentag S, Worthen GS: IL-17A and TNFalpha exert synergistic effects on expression of CXCL5 by alveolar type II cells in vivo and in vitro. J Immunol 2011;186:3197-3205.

31 Pera T, Zuidhof AB, Smit M, Menzen MH, Klein T, Flik G, Zaagsma J, Meurs H, Maarsingh H: Arginase inhibition prevents inflammation and remodeling in a guinea pig model of chronic obstructive pulmonary disease. J Pharmacol Exp Ther 2014;349:229-238. 